7. Reprod. Fert. (1971) 27, 145-147

\title{
ELIMINATION OF SPERMATOZOA IN THE URINE OF ISOLATED MALE RATS
}

\author{
E. FERNÁNDEZ-COLLAZO, E. VIDELA AND J. C. PEREYRA \\ Centro de Investigaciones sobre Reproducción, \\ Facultad de Medicina, Buenos Aires, Argentina
}

(Received 4th May 1971, revised 15th Fune 1971)

Evidence has been reported to indicate that non-ejaculated spermatozoa in adult animals of different mammalian species may be eliminated by phagocytosis (Morgenstern, 1924), voiding in the urine (Oslund, 1928; Wilhelm \& Seligmann, 1937; Bolliger \& Carrodus, 1938), and dissolution into the vas deferens (Simeone \& Young, 1931), though the phenomenon does not appear to have been studied quantitatively.

The purpose of the present study was to investigate the presence and numbers of spermatozoa in the urine of isolated male rats.

Six adult male rats of the Wistar strain, weighing 277 to $385 \mathrm{~g}$, and of proven fertility, were separated from the female rats with which they had been mated. After 2 weeks, they were kept in individual metabolic cages, where the urine passed through a glass funnel into a $125-\mathrm{ml}$ Erlenmeyer flask containing $5 \mathrm{ml}$ of a solution of $1 \%$ thimerosal in saline. The flasks were collected in the morning and the evening. Care was taken to avoid sperm losses by washing the funnel with saline solution and adding this liquid to the flask.

To assess the sperm concentration, the flask was shaken and a drop of the liquid was examined under a light microscope $(\times 100)$. When more than five spermatozoa per field were observed, a count was carried out directly in a Neubauer counting chamber. As the total volume was known, the results were expressed as the total number of spermatozoa eliminated. If there were less than five spermatozoa per field, $10 \mathrm{ml}$ of the material was centrifuged at 2000 $\mathrm{rev} / \mathrm{min}$ for $10 \mathrm{~min}, 9 \mathrm{ml}$ of the supernatant were discarded and the sediment was resuspended in the remaining liquid. The count was carried out as previously described. The results of the morning and evening sperm counts carried out daily for each animal were added and represented the total number of spermatozoa eliminated in $24 \mathrm{hr}$.

Spermatozoa were found every day in the urine of four of the six rats during the 15 days of the experiment. In Rat 1, no spermatozoa were observed on Day 9 and in Rat 4, the same result was obtained on Days 1, 5 and 10.

The mean number of spermatozoa eliminated in the urine per day and per rat was $392,948 \pm 87,042$. The number of spermatozoa eliminated by each rat varied considerably from day to day, showing a cyclic tendency. The daily differences for individual rats were not similar for all rats, thus explaining the absence of significant difference between days shown by the variance analysis (Table 1). 
Occasionally, clumps of spermatozoa were found resembling those normally observed in the vas deferens.

Even allowing for the fact that with the technique used some spermatozoa may be lost, the results clearly show that elimination in the urine is one route for the disposal of non-ejaculated spermatozoa. This confirms the hypothesis of Oslund, which was based on finding spermatozoa in the urethra of dogs, rats and guinea-pigs. It also agrees with the published evidence for man (Wilhelm \& Seligmann, 1937) and marsupials (Bolliger \& Carrodus, 1938). Simeone \& Young (1931), however, did not find spermatozoa in the urine of adult guineapigs.

Elimination of spermatozoa in the urine in the absence of ejaculation is supported by the demonstration of the passage of radiopaque substance from the vas deferens to the bladder (Wilhelm, 1935; MacMillan \& Harrison, 1955).

\section{TABLE 1}

ANALYSIS OF VARIANCE FOR ELIMINATION OF SPERMATOZOA $†$ IN THE URINE OF ISOLATED RATS

\begin{tabular}{l|r|c|c}
\hline \multicolumn{1}{c|}{ Source of variation } & d.f. & Mean square & $F$ \\
\hline Between rats & 5 & $6718 \cdot 4$ & $2 \cdot 23^{*}$ \\
Between days & 14 & $2936 \cdot 3$ & $0 \cdot 97^{*}$ \\
Interaction & 70 & $3017 \cdot 4$ & \\
\hline
\end{tabular}

$\dagger$ Values expressed as numbers of spermatozoa $\times 10^{3}$.

$* P>0.05$.

The disappearance of spermatozoa from the vas deferens and the semen following vasectomy, observed by Kirillov (1938) in the bull and by Freund \& Davis (1969) in man, does not support the concept of a specific elimination route. The antispermatic agglutinins which have been described following vasectomy in man (Phadke \& Padukone, 1964; Rümke, 1967) and in rat (Rümke \& Titus, 1970) suggest that resorption of spermatozoa in the seminal tract does not suffice as the only disposal route and that the presence of spermatozoa may trigger an autoimmune antispermatic mechanism.

\section{REFERENCES}

Bolliger, H. \& Carrodus, A. L. (1938) Spermatorrhoea in Trichosurus vulpecula and other marsupials. Med. F. Aust. ii, 1118.

Freund, M. \& Davis, J. E. (1969) Disappearance rate of spermatozoa following vasectomy. Fert. Steril. 20, 163.

KiriLLov, V.S. (1938) The role of the ampullae of the vasa deferentia in the formation of the ejaculate in the bull. (Trans.) Probl. Zivotn. 2, 189. (In: Anim. Breed. Abstr. 5, 22).

MacMillan, E. W. \& Harrison, R. G. (1955) The rate of passage of radiopaque medium along the ductus epididymis of the rat. Stud. Fert. 7, 35.

Morgenstern, S. (1924) Zur Frage der Spermiophagie. Virchows Arch. path. Anat. Physiol. 250, 648.

Ossund, R. M. (1928) The physiology of the male reproductive system. F. Am. med. Ass. 90, 829.

Phadke, A. M. \& Padukone, K. (1964) Presence and significance of autoantibodies against spermatozoa in the blood of men with obstructed vas deferens. 7. Reprod. Fert. 7, 163.

Rümke, PH. (1967) Sperm-agglutinating autoantibodies in relation to male infertility. Proc. R. Soc. Med. 61, 275. 
Rüмке, Рн. \& Trrus, M. (1970) Spermagglutinin formation in male rats by subcutaneously injected syngeneic epididymal spermatozoa and by vasoligation or vasectomy. $\mathcal{F}$. Reprod. Fert. 21, 69.

Simeone, F. A. \& Young, W. C. (1931) A study of the function of the epididymis. IV. The fate of nonejaculated spermatozoa in the genital tract of the male guinea-pig. F. exp. Biol. 8, 163.

WilheLM, S. F. (1935) Observations on emptying of vasa deferentia and seminal vesicles. F. Urol. 34, 284.

Wilhelm, S. F. \& Seligmann, A. W., Jr (1937) Spermatozoa in urine. Am. F. Surg. 35, 572. 